\title{
A confound in the application of fixed-ratio schedules to the social behavior of male Siamese fighting fish (Betta splendens)
}

\author{
PAUL M. BRONSTEIN \\ University of Michigan, Flint, Michigan
}

\begin{abstract}
Male Siamese fighting fish were presented with a response-contingent mirror image on either CRF or FR3 schedules. It was concluded that the many differences between the groups were understandable as the result of schedule-related changes in the duration of exposure to conspecific images rather than to differences in the frequency of stimulation, and were due to the releasing and not the reinforcing functions of stimulation. The frequency distribution of agonistic behaviors in bettas also was shown to be bimodal: Some males fought intensely, whereas others escaped and attacked little. Furthermore, it was suggested that bettas' multivariate agonistic sequence has not yet been subjected to an unambiguous operant analysis.
\end{abstract}

The current paper extends somewhat a recent set of articles on Siamese fighting fish (Betta splendens) from this laboratory (see Bronstein, 1980, 1981a, 1981b, 1982, 1983a, 1983b, 1984, in press-a, in press-b). The general thrust of those papers is that, first, bettas appear to possess an agonistic/reproductive strategy similar to that of some wild-living and little-domesticated teleosts, and that their social behavior may be sensibly analyzed as an integrated social system. Second, the papers have criticized the many studies of these fish that have grown from the traditions of operant psychology (at least 2 decades of such work). It appears that the Skinnerianstyle investigations often have (1) confused behaviors elicited by social cues with socially reinforced responses, (2) interpreted species-specific acts as learning (Bronstein, $1981 \mathrm{~b}$ ), and (3) distorted and mismeasured behavior in such a way as to operationally define animals' movements in escape of social contact as motivation to increase aggression (Bronstein, 1984, in press-b). Thus, psychologists' commitment to "mechanisms" and "processes" (in short, a fascination with Cartesian reductionism) has spawned procedures that, theoretically, could isolate hypothetical intrapsychic events. However, in the case of bettas, this style of research appears to have disorganized and denatured the animals' functional social system while simultaneously shifting attention away from the actual content and meaning of that social system.

This paper was supported by grants from the Faculty Development Committee of the University of Michigan-Flint, A Rackham grant from the University of Michigan-Ann Arbor, and Grants MH 38792-01 and MH 33389-01 from the National Institute of Mental Health. I am grateful to Larry Atherton, Jr., and William Mykolajenko for their excellent technical aid and to Colleen Pace for her secretarial assistance. Requests for reprints should be addressed to: Paul M. Bronstein, Department of Psychology, University of Michigan, Flint, MI 48502-2186.

\section{EXPERIMENT 1}

One series of observations (Bronstein, in press-b) found groups of male bettas to be bimodally distributed on indices of agonistic behavior. When tested with either a mirror or a live conspecific for $30 \mathrm{~min}$ or less, some fish remained close to the source of social stimulation and attacked persistently. However, a second subgroup escaped relatively far from the conspecific image and showed little attack behavior. (Attack and display activities in male bettas appear to occur only when subjects are within $12 \mathrm{~cm}$ of each other-see Bronstein, 1983b, and Klein, Figler, \& Peeke, 1976.) The current study used 90-min mirror-exposure tests and successfully replicated the results of Bronstein (in press-b).

\section{Method}

Subjects in both experiments were domesticated male bettas obtained from local suppliers. The fish were red, blue-green, or purple and were kept in individual glass containers (1-2 liters) in visual isolation. Feedings of flaked food and freshly thawed brine shrimp (Artemia spp.) occurred twice daily on Mondays through Fridays; the colony was heated to $28( \pm 2){ }^{\circ} \mathrm{C}$, and overhead fluorescent lights were on from 0800 to $2200 \mathrm{~h}$ daily.

The fish were netted and placed individually into either a large rectangular aquarium $(47.5 \times 152.4 \mathrm{~cm})$ or a small tank $(40.4 \times 20.3 \mathrm{~cm})$. Both of these glass vessels were visually isolated from other aquaria, were filled to a depth of $12.7 \mathrm{~cm}$ with water in which other fish had swum, and also contained undyed gravel as flooring material ( $3 \mathrm{~cm}$ deep). After the fish had swum undisturbed for $10 \mathrm{~min}$, the outside of one of the short walls of each tank was covered with a mirror for $90 \mathrm{~min}$. Vertical lines had previously been drawn on the outside of the long walls and $7.6 \mathrm{~cm}$ from the mirrors. The number of seconds that each subject spent with its eyes within $7.6 \mathrm{~cm}$ of the mirror (i.e., approach duration) was recorded by an observer using a stopwatch.

\section{Results}

As noted in Figure 1, bimodal distributions of approach times were apparent in both the small and large 


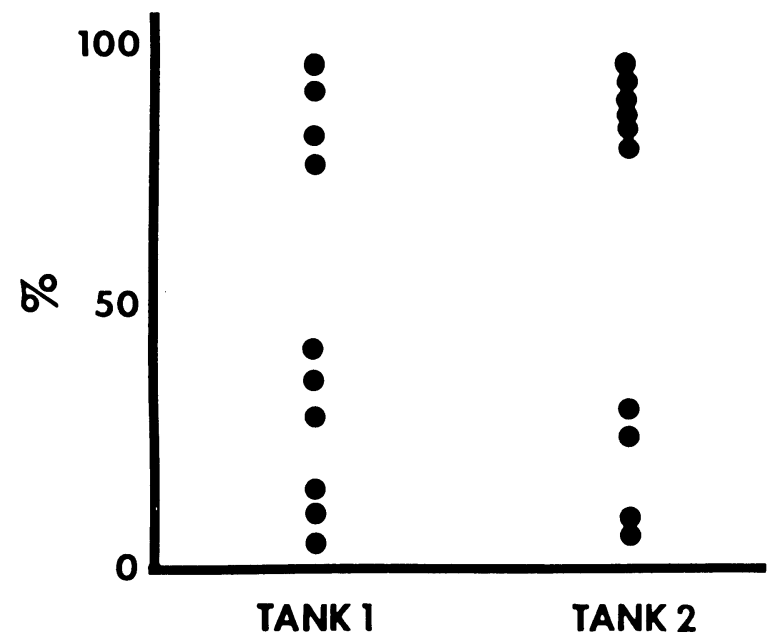

Figure 1. The percentage of a 90-min session that each subject (represented by a dot) remained between the approach line and opponent wall in Experiment 1. Tank 1 was $40.4 \mathrm{~cm}$ long; Tank 2 was $152.4 \mathrm{~cm}$ long.

aquaria. Moreover, ancillary observations showed that fish within $7.6 \mathrm{~cm}$ of their mirror images were almost always attacking that stimulus, that is, biting and issuing frontal and lateral displays. Thus, the current results extend prior reports of a bimodal distribution of approach and attack behaviors in samples of domesticated Betta splendens males (Bronstein, in press-b). Finally, escape behaviors often were rapid and explosive among males showing low approach durations. Swimming maneuvers carrying fish the entire length of the large tank $(152.4 \mathrm{~cm})$ in less than $3 \mathrm{sec}$ were observed.

\section{EXPERIMENT 2}

The evidence favoring the existence of a process of "social reinforcement" is based almost entirely on experiments with Siamese fighting fish (see Hogan \& Roper, 1978). Male bettas typically have been placed in small tanks and presented with, say, 20-sec exposure to a mirror contingent upon their moving toward the wall where the mirror was available. Under such conditions, approaches to the mirror-stimulation site increase reliably. Furthermore, such movements cease soon after the mirror is made unavailable. The reinforcementbased interpretation of these highly replicable data is that social stimulation acts retroactively to positively reinforce approach responses made by the fish. Such alleged responses are discussed as having been extinguished when the removal of visual stimulation is correlated with a decrement in an animal's swimming behavior.

However, Bronstein (1981b, 1983a, 1984, in press-b) has criticized the reinforcement-based interpretation of social behavior in bettas. It was shown that most, if not all, changes in behavior used to justify the existence of a "social-reinforcement process" in these animals could not be differentiated from the species-specific move- ments elicited proactively by conspecific cues. Alleyway, free-operant, and T-maze data can all be explained, not as reinforced operants, but as conflict behavior released at the start of a male-male encounter and then canalized by the physical characteristics of various apparatuses-that is, distorting movement and restricting contact with releasers. "Extinction" effects can be understood as the rapid deterioration of agonistic behavior following the elimination of social (i.e., visual) cues (see Bronstein, 1981a, 1983a).

The present study is an extension of the criticisms of reinforcement-based studies using bettas. In attempting to show control over bettas' swimming by operant contingencies, Hogan, Kleist, and Hutchings (1970) attempted to manipulate "magnitude of reinforcement" (the duration of mirror stimulation) following "responses" (transits through a short tunnel). No relation was found between behavior and stimulus duration; but this null finding, it now appears, was an artifact of the distortions inherent in operant techniques. At the start of a male-male encounter, the intensity of aggression is directly proportional to the persistence with which a conspecific image is both visible and close to a subject (Bronstein, 1983a). Given the details of bettas' agonistic ethogram, plus the great importance of the duration of social stimulation in controlling that behavior, it seems likely that attempts to socially reinforce these fish on various free-operant-ratio schedules have confounded the different ratios with variations in the duration of stimulation (cf. Bronstein, 1981b; Hogan et al., 1970; Turnbough \& Lloyd, 1973). Whether this potential confound exists depends both upon the specific ratios employed and upon interanimal variability, which, as seen in Experiment 1 (above), can be enormous.

All ratio-schedule studies of "social reinforcement" in bettas seem of questionable validity because of their potential in causing frequency and duration of stimulation to covary. Experiment 2 was an attempt to manipulate ratio schedules while assessing this possible confound by measuring the duration of mirror stimulation.

\section{Method}

The test environment was a glass aquarium $(40.4 \mathrm{~cm}$ long, $25.0 \mathrm{~cm}$ high, and $20.3 \mathrm{~cm}$ wide); undyed gravel $(2 \mathrm{~cm}$ deep) covered the bottom of this tank. A sheet of white styrene was placed inside and parallel to the long walls of the tank. This divider reduced the width of the test chamber to $15 \mathrm{~cm}$. Tap water left standing for at least $24 \mathrm{~h}$ and in which no fish had swum was used, and there were 15-20 liters of water in the tank. Finally, the aquarium had two vertical lines drawn on each long side. One line was $7.6 \mathrm{~cm}$ from the adjacent wall. (That short side, $25.0 \times 20.3 \mathrm{~cm}$, will be referred to subsequently as the "opponent wall"; the line will be known as the "approach line.") The second line (the "escape line") was $22.9 \mathrm{~cm}$ away from the opponent wall; the distance between lines was $15.3 \mathrm{~cm}$.

A sheet of gray plastic was placed outside the opponent wall. This covering was a shutter that was moved aside mechanically to reveal a mirror covering the entire opponent wall. The subjects were netted and transferred to the test arena individually and permitted to adapt to the test arena for $10 \mathrm{~min}$. The fish were assigned randomly to either of two treatment conditions. Each animal in Group CRF $(n=9)$ had a mirror presented every time it swam across the approach line toward the opponent wall. 
For Group FR3 $(n=6)$, three crossings of the approach line were required before the mirror was shown; and for both groups, the mirror was exposed for $25 \mathrm{sec}$ each time a criterion response occurred. The fish were placed in the test aquarium, adaptation was permitted, and then a $150-\mathrm{min}$ trial was begun $(1015-\mathrm{min}$ blocks).

A panel of buttons connected to electromechanical timers and counters was used to record the animals' movements. The following behaviors were recorded, with the location of a fish determined by the relation of its eye to the lines drawn on the tanks, and with durations resolved to within $1 \mathrm{sec}$ : (1) approaches-the frequency of entries to within $7.6 \mathrm{~cm}$ of the opponent wall; (2) attacks-the number of entries to within $7.6 \mathrm{~cm}$ of the opponent wall while the mirror was visible; (3) approach duration-the time an animal spent within $7.6 \mathrm{~cm}$ of the opponent wall; (4) display frequency-the number of times a gill display was initiated; (5) display duration-the number of seconds a fish kept its gill covers erect; (6) escapes-the frequency of movements across the escape line while moving away from the opponent wall; (7) exits-escapes that occurred while the mirror was visible; $(8)$ escape duration-time spent at least $22.9 \mathrm{~cm}$ from the opponent wall; (9) nest building-time taken by a fish to gulp air at the surface of the water and express air at the water surface through its mouth or gills; and (10) mirror-exposure duration-the number of seconds the mirror was visible. The position of a fish while displaying, that is, whether the animal was in the approach area, also was recorded. Attacks, exits, and mirror-exposure durations were recorded only for the session as a whole; all other measures were noted for each 15-min block independently. Finally, mean approach bouts were calculated per 15-min block for each animal. This measure was defined as the average number of seconds a fish remained in the approach zone (within $7.6 \mathrm{~cm}$ of the opponent wall) each time it entered this area.

\section{Results and Discussion}

The mirror was available for Group CRF longer than for Group FR3 $\left[\operatorname{mean}_{\mathrm{CRF}}=3,185 \mathrm{sec}, \operatorname{mean}_{\mathrm{FR} 3}=\right.$ $843 \mathrm{sec} ; \mathrm{t}(13)=3.75, \mathrm{p}<.01$ ] . Consequently, it is not possible to interpret any intergroup differences as being due either to the rate or the frequency of animals' encounters with their mirror images. Mirrorexposure durations were confounded with the nominal independent variable (ratio schedule), and stimulus duration might have been responsible for any effects attributed to schedule contingencies, both in this experiment and in other studies in which ratios were manipulated but in which duration of exposure to conspecific images was not assessed (Bronstein, 1981b; Hogan et al., 1970; Turnbough \& Lloyd, 1973).

Data were analyzed using a $2 \times 10$ mixed analysis of variance with the two schedules of reinforcement and the 1015 -min blocks as the orthogonal independent variables. As seen in Figure 2, the fish spent progressively less time in the escape zone as testing proceeded-a reliable blocks effect $[F(9,117)=29.27, p<.001]$. The groups $\mathrm{x}$ blocks interaction was also reliable for this measure, as well as for approach duration $-[\mathrm{Fs}(9,117) \geqslant$ 2.82 , ps < .05]. Group CRF animals increased their time in the approach area and spent less and less time in the escape zone as testing proceeded; over blocks, Group FR3 fish did not show as much of a change in their attraction to the opponent wall. The relatively more persistent stimulation of the Group CRF animals
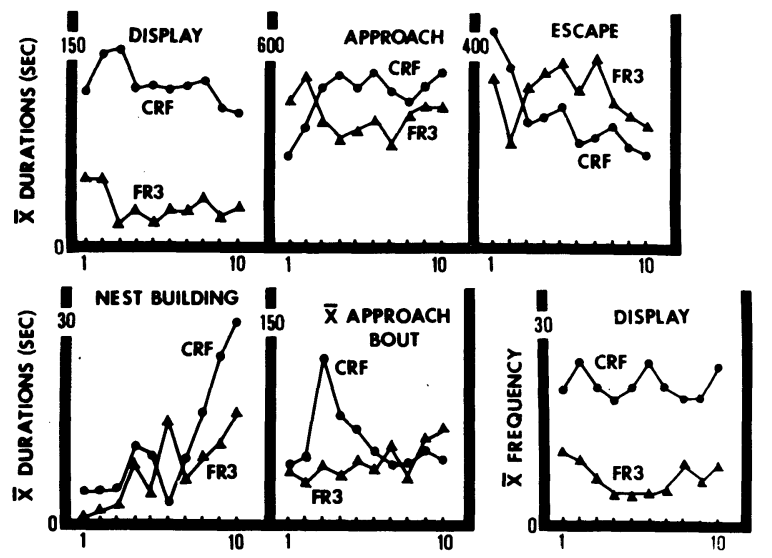

Figure 2. The results on six dependent variables as a function of reinforcement schedule (CRF or FR3) and 10 15-min blocks (represented on the horizontal axis of each panel).

caused some of them to eliminate their escape movements and to remain close to the site of visual stimulation as testing proceeded. These fish were advancing to a more intense stage of fighting than the Group FR3 subjects. This relatively focused pattern of swimming is typical of actual fights between males (Bronstein, 1981a, in press-a) and occurs in response to relatively persistent proximal social stimulation (Bronstein, 1983a). There was also a two-way interaction on the nest-building measure; Group CRF increased its rate of nest building more rapidly than Group FR3 $[\mathrm{F}(9,117)=2.82$, $\mathrm{p}<$ $.005]$.

The display indices were the only behaviors on which the two groups could be differentiated. Group CRF animals spent more time displaying and also displayed a greater number of times than did Group FR3 fish $[\mathrm{Fs}(1,13) \geqslant 7.89$, ps $<.05]$. The decrement in display frequency among Group FR3 animals during the middle of the session also produced a reliable groups $\mathrm{x}$ blocks interaction $[F(9,117)=5.97, p<.001]$. For both groups, between $88 \%$ and $98 \%$ of the instances and duration of display occurred in the approach zone; there were no reliable differences between treatments. These data add to the evidence that frontal display in male bettas is primarily a reaction to proximate conspecifics (Bronstein, 1981b, 1983a, 1983b; Klein et al., 1976). Finally, there were no main effects or interactions when attacks, approaches, mean approach bouts, escapes, and exits were examined statistically.

Taken together, these data describe behaviors typical of male bettas at the start of combat, when confronting an aggressively hesitant opponent, or when presented with brief bouts of intermittent social stimulation (Bronstein, 1981a, 1981b, 1983a, in press-a). Fish approached the site of social stimulation, displayed when near the mirror, and then fled. That is, social stimulation contingent on an allegedly operant response produces the same behaviors as conspecific images occurring in a noncontingent manner, provided the subject- 
to-stimulus distance is similar in both situations (see Bronstein, 1981b, 1983b). Furthermore, fish display more, become more variable, and shift their average position slightly toward the site of social stimulation as the amount of social stimulation is increased. Each of these findings is consistent with the conclusion that "socially reinforced" behaviors in male bettas are actually opponent-assessment maneuvers elicited by replicas of stimulation typical of the start of combat (cf. Bronstein, 1983a). Furthermore, all applications of ratio schedules to bettas' social behavior lack internal validity, since such studies confound different rates of stimulus onset either with covariations in duration of stimulation or with changes in subject-to-stimulus distances (cf. Bronstein, 1981b, 1983a).

\section{REFERENCES}

Bronstein, P. M. (1980). Betta splendens: A territorial note. Bulletin of the Psychonomic Society, 16, 484-485.

Bronstein, P. M. (1981a). Commitments to aggression and nest sites in male Betta splendens. Journal of Comparative and Physiological Psychology, 95, 436-449.

Bronste in, P. M. (1981b). Social reinforcement in Betta splendens: A reconsideration. Journal of Comparative and Physiological Psychology, 95, 943-950.

Bronstein, P. M. (1982). Breeding, paternal behavior, and their interruption in Betta splendens. Animal Learning \& Behavior, 10, 145-151.
Bronstein, P. M. (1983a). Agonistic sequences and the assessment of opponents in male Betta splendens. American Journal of Psychology, 96, 163-177.

Bronstein, P. M. (1983b). Onset of combat in male Betta splendens. Journal of Comparative Psychology, 97, 135-139.

Bronstein, P. M. (1984, April). Toxiphobia, "social reinforcement, " comparative psychology, and Patrick J. Capretta. Paper presented at the meeting of the New York Academy of Sciences, New York.

Bronstein, P. M. (in press-a). Agonistic and reproductive interactions in Betta splendens. Journal of Comparative Psychology.

Bronste in, P. M. (in press-b). Predictions of dominance in male Betta splendens. Journal of Comparative Psychology.

Hogan, J. A., Kleist, S., \& Hutchings, C. S. L. (1970). Display and food as reinforcers in the Siamese fighting fish (Betta splendens). Journal of Comparative and Physiological Psychology, 70, 351-357.

Hogan, J. A., \& Rober, T. J. (1978). A comparison of the properties of different reinforcers. In J. S. Rosenblatt, R. A. Hinde, C. Beer, \& M.-C. Busnel (Eds.), Advances in the study of behavior (Vol. 8). New York: Academic Press.

Klein, R. M., Figler, M. H., \& Peeke, H. V. S. (1976). Modification of consummatory (attack) behavior resulting from prior habituation of appetitive (threat) components of the agonistic sequence in male Betta splendens (Pisces: Belontiidae). Behaviour, 58, 1-25.

Turnbough, P. D., \& Lloyd, K. E. (1973). Operant responding in Siamese fighting fish (Betta splendens) as a function of schedule of reinforcement and visual reinforcers. Journal of the Experimental Analysis of Behavior, 20, 355-362.

(Manuscript received for publication March 19, 1984.)

\section{ANNOUNCEMENT}

\section{Change in Editorship}

Robert Bjork completes his regular 4-year term as editor of Memory \& Cognition in 1985. The Publications Committee of the Governing Board of The Psychonomic Society is pleased to announce that Alice F. Healy has agreed to be the next editor (1986-1989). After January 1, 1985, please send manuscripts to Dr. Healy at: Department of Psychology, University of Colorado, Muenzinger Building, Campus Box 345, Boulder, CO 80309. 